\title{
Conjugated Monoclonal Antibody CC49
}

National Cancer Institute

\section{Source}

National Cancer Institute. Conjugated Monoclonal Antibody CC49. NCI Thesaurus. Code C2747.

A immunoconjug ate comprised of a monoclonal antibody directed against the pancarcinoma antigen TAG-72.conjugated to PA-DOTA, a bifunctional chelant. TAG-72 is a protein/sug ar complex found on the surface of many cancer cells, including breast, colon, and pancreatic cancer cells. (NCI04) 